\title{
A educación, compromiso e responsabilidade dos concellos democráticos en Galicia (1978-2018)
}

\author{
(Education, Commitment and Responsibility of Democratic \\ City Councils in Galicia (1978-2018)
}

\author{
Héctor POSE PORTO \\ Universidade da Coruña \\ José Antonio CARIDE GÓMEZ \\ Universidade de Santiago de Compostela
}

\begin{abstract}
RESUMO: Coa vontade explícita de alentar a construción dun novo país en nome do desenvolvemento e da democracia local, o texto que se presenta sitúa os seus argumentos nunha lectura histórica do quefacer educativo municipal en Galicia, dende os últimos anos da década dos setenta do pasado século ata a actualidade (1978-2018). Sendo así, os seus contidos articúlanse arredor de catro eixes temáticos principais: a tensión entre o local e o global na emerxencia dun novo escenario para a educación no tránsito cara ao século XXI; a acciónintervención educativa nos e dos concellos como un compromiso cívico, pedagóxico e político; as competencias municipais en materia educativa na complicada concreción das palabras en feitos; a misión educadora dos concellos atendendo a distintas perspectivas e iniciativas da acción-intervención educativa, dende a infancia ata a vellez, nas institucións escolares e nun amplo conxunto de axentes, entidades e organizacións comunitarias.
\end{abstract}

PALABRAS CLAVE: municipios; administración local; pedagoxía social; educación; cidadanía.

ABSTRACT: This article is intended as a spur to development and local democracy as the foundation of a new country. The text offers a historical interpretation of the educational endeavours of local government in Galicia from the late 1970s to the present (1978-2018). The analysis focuses on four main themes: tension between local and global aspects of the emergence of a new educational scenario during the transition to the twenty-first century; educational action-intervention in and by local government as a civic, pedagogical and political commitment; the complicated task for local government of putting words into action in relation to education; the educational mission of local government to address the different perspectives and initiatives of educational action-intervention, from childhood to old age, in schools, institutions and organisations of all kinds.

KEYWORDS: local government; local administration; social pedagogy; education; citizens. 


\section{Introdución: construír de novo o país en nome da democracia local}

Fai apenas catro décadas, na que ao paso do tempo identificamos como a transición democrática española, a cidadanía recuperaba a oportunidade de escoller aos seus representantes políticos nas corporacións locais; e, con ela, a ilusión por renovar cargos, formas, discursos e políticas acordes coa Constitución referendada en plebiscito o 6 de decembro de 1978. Acontecía o 3 de abril de 1979, acudindo ás furnas 16.621 .868 persoas ( $62,51 \%$ do censo eleitoral), facendo partícipes aos municipios da nova organización territorial do Estado (cap. 1, art. 137 da Constitución Española), en converxencia coas provincias e as Comunidades Autónomas que se constitúan, sendo todas elas entidades que gozarán de autonomía para a xestión dos seus respectivos intereses.

Deixar atrás a "longa noite de pedra" que poemou o bardo Celso Emilio Ferreiro, significaba abrir as fiestras a refachos de liberdade e esperanza tras a extensa e dura etapa ditatorial franquista e as disposicións emanadas da Ley de Bases de Régimen Local de 1945, no que os concelleiros serían designados -mesmo facendo uso da expresión "eleitos"- segundo a súa pertenza aos terzos "familiar" (entre os veciños, cabeza de familia), "sindical" (a instancias dos organismos sindicais) e "corporativo" (propostos polos gobernadores civís aos concellos a partir da súa pertenza a entidades económicas, culturais e profesionais do municipio).

Construír de novo o país, coa implicación e o compromiso das recén creadas e/ou rehabilitadas forzas políticas, pasaba por edificalo dende os alicerces que representaban, ou deberían representar, os municipios nas coordenadas históricas que alentaran a súa creación nos inicios do século XIX'. A cultura da democracia, sustentada na conciencia participativa de que o público é un ben todos ${ }^{2}$, retornaría ás Administracións Locais convidando ás persoas a facer outras lecturas das súas políticas e do quefacer municipal. E, inevitablemente, a prácticas cívicas coas que conciliar o respecto ás liberdades individuais cos valores colectivos que aniñan na xustiza, a igualdade e a diversidade.

Nelas o territorio é un lugar antropolóxico no que se proxectan uns sinais identitarios, relacionais e sociohistóricos vertebrados arredor de múltiples circunstancias de natureza simbólica e material: un tempo-espazo vital e patrimonial nas que se insire a vida cotiá das persoas ${ }^{3}$, dando resposta ás necesidades económicas e socioambientais ${ }^{4}$ nas que se sustenta calquera expectativa do desenvolvemento individual e colectivo, no local e no global. De aí que aloumiñar a renacida democracia española, décadas despois da fenecida II República (1931-1936), pasara por artellar a gobernanza dende, nos e cos concellos: coas persoas e para as persoas, sendo conscientes de que todo, ou case, estaba por (re) facer a favor do seu benestar e dos dereitos cívicos.

\footnotetext{
${ }^{1}$ Enrique Orduña, Historia del municipalismo español (Madrid: Lustel, 2005)

2 Salvador Giner et alt., La cultura de la democracia: el futuro (Barcelona: Ariel, 2000)

${ }^{3}$ Marc Augé, Los no lugares: espacios del anonimato (Barcelona: Gedisa, 2006)

${ }^{4}$ José Antonio Caride, "Educación social, ciudadanía y desarrollo en el escenario de las comunidades locales", en Espacios para el desarrollo local, edit. Emilio Lucio-Villegas, (Barcelona: Editorial PPU, 2006), 17-61.
} 
Neste escenario, inzados de arelas, os/as primeiros/as edís eleitos/as por sufraxio estrearon os seus cargos falando en galego, asfaltando rúas, alumeando camiños, oradando o chan para o saneamento e as comunicacións ${ }^{5}$. As dotacións básicas para unha comunidade, á ollos das renovadas corporacións, darían prioridades ás "obras"... como se acabaramos de sobrevivir a un conflito bélico. Foi así en moitos dos concellos, nomeadamente, do rural galego, aínda que tamén en moitos dos centros e periferias das vilas e cidades, sen que o afán por "equiparnos", con razóns ou sen elas, teña cesado ata o día de hoxe; agás, se cabe, nos momentos máis álxidos da crise económica dos derradeiros anos, sometidos aos rigores do Real Decreto-Lei 8/2010, de 20 de maio, polo que se adoptan medidas extraordinarias para a redución do déficit público, que no seu capítulo VI, art. 14, prevé diversas accións en materia económico-financeira de aplicación ás entidades locais (BOE de 24 de maio de 2010).

\section{Local e global, ou a emerxencia dun novo escenario para a educación no tránsito ao século XXI}

Poñer a énfase nas realidades locais, no que teñen de territorio humanizado co que se delimita xeográfica e normativamente a convivencia nun determinado espazo-tempo, implicaría na rexurdida democracia española, dotar ao seu sistema político dunha gobernanza multinivel ${ }^{6}$ dentro e fóra das súas fronteiras ${ }^{7}$. Nela, todas as autoridades e institucións municipais, provinciais, rexionais, nacionais e supranacionais-xogarán un papel relevante, non só na división dos poderes e das corresponsabilidades que se lles atribúen en cada caso, senón e sobre todo, na evolución de dous procesos que marcarán decisivamente o futuro do país: dunha banda, a descentralización do Estado, especialmente na conformación e atribución de competencias -propias e/ou compartidas- ás nacentes Comunidades Autónomas; doutra, a apertura ao mundo, comezando pola integración europea o a pertenza -con atribucións plenas-aos organismos internacionais no seo das Nacións Unidas.

A tensión global-local que emerxe coa era da información e a sociedade rede ${ }^{8}$ no tránsito ao novo século e milenio, será indisociable -tal e como reflicten distintas análisesdunha certa perda de autoridade na Administración Estatal, posibilitando novas formas de facer política e de xestionar os bens comúns, en parte como un modo de dar "resposta ás deficiencias percibidas no modelo de goberno e de gobernaza baseado no Estadonación" ${ }^{\prime \prime}$. En pleno contexto globalizador ${ }^{10}$ as sociedades gañan en heteroxeneidade, as identidades se reforzan, as vellas centralidades se erosionan e condición cidadá, tratando

\footnotetext{
${ }^{5}$ Xan Bouzada, Escola, cultura e vida comunitaria nun concello galego: Moaña, (Moaña: Concello de Moaña, 1989) ${ }^{6}$ Lisbet Hooge e Gary Marks. Multi-level Governance and European Integration (Lanham, MD: Rowman \& Littlefield, 2001).

${ }^{7}$ Ian Bache e Matthew Flinders, coords., Multi-level Governance. (Oxford: Oxford University Press, 2004)

${ }^{8}$ Jordi Borja e Manuel Castells, Local y global: la gestión de las ciudades en la era de la información (Madrid: Santillana-Taurus-UNHCS, 1997).

${ }_{9}^{9}$ Andy Pike, Andrés Rodríguez-Pose e John Tomaney, Desarrollo local y regional (Valencia: Instituto Interuniversitario de Desarrollo Local de la Universitat de València, 2011), 198.

${ }^{10}$ Quim Brugué e Ricard Gomá coords. Gobiernos locales y políticas públicas: bienestar social, promoción económica y territorio (Barcelona: Ariel, 1998).
} 
capear o vendaval neoliberal, persiste en demandar un compromiso decidido co benestar colectivo, con modos de actuar máis relacionais que xerárquicos. Un quefacer respecto do que as institucións educativas ${ }^{11}$, nomeadamente a escola ${ }^{12}$, a acción-animación sociocultural ${ }^{13}$ e o traballo social territorializado $0^{14}$, están convocados a desempeñar un protagonismo clave.

A mobilización do potencial endóxeno, a adopción de novos mecanismos de participación social, a elaboración de plans estratéxicos de acción local, a implementación de axendas 21 locais, etc. serán algunhas das actuacións postas ao servizo das políticas públicas e da iniciativa cidadá, situando os seus horizontes nun desenvolvemento globallocal "alternativo", económica e ambientalmente sostible, ética e socialmente inclusivo. Cuestións esenciais que, como lembran Díez e Rodríguez (2018) ${ }^{15}$, suscitan preguntas arredor da cidadanía que buscamos, dos estilos de vida que defendemos, das relacións sociais que desexamos propiciar, etc. fronte á reprodución e a lexitimación social do discurso neoliberal hexemónico.

Antes, coma hoxe, concibir o "local" coma comunidade, na que se prefiguran e configuran múltiples e complexas interaccións entre individuos e colectivos, que padecen e se benefician dos achaques e avances socioeconómicos globais, supoñía e supón un desafío para os xestores do público, pouco ou nada alentados por unha pedagoxía social e política de amplas miras, que trascenda o curtoplacismo eleitoral, os intereses partidistas ou a representatividade institucionalizada. Moito menos aínda, cando -como aconteceu no postfranquismo- gobernar en liberdade, para quen foi criado nun contexto privado dela, requiría dunha decidida vontade de cambio e transformación social, congruente cos principios democráticos e as virtudes da "polis". Neles, a calidade de vida comunitaria téstase con novos indicadores, de xeito que os servizos, equipamentos e actividades que se promovan mariden con innovadoras formas de participar, decidir e facer. Intuílo politicamente é posicionarse para desenvolver outras prácticas municipais nos ámbitos do lecer, a cultura, 0 medio ambiente, a muller, a educación ${ }^{16}$. Nada que se prece na economía, na demografía, no emprego, na innovación, no benestar, na comunicación, na lingua, na sociocultura, na saúde, nas infraestruturas ou na articulación do territorio..., será alleo aos desafíos e

\footnotetext{
${ }^{11}$ Montse Castro et al., La escuela en la comunidad. La comunidad en la escuela (Barcelona: Graô, 2007).

12 Joan Subirats coord., Gobierno Local y Educación: la importancia del territorio y la comunidad en el papel de la escuela (Barcelona: Ariel, 2002)

${ }^{13}$ Roberto Gómez de la Iglesia coord., Cultura, Desarrollo y Territorio (Vitoria-Gasteiz: Xabide, 2001); Aina Calvo. La animación sociocultural: una estrategia educativa para la participación (Madrid: Alianza Editorial, 2002); Alfóns Martinell coord. Cultura y desarrollo: un compromiso para la libertad y el bienestar (Madrid: Fundación CarolinaSiglo XXI editores, 2010)

${ }^{14}$ Mejed Hamzaoui, El trabajo social territorializado: las transformaciones de la acción pública en la intervención social (Valencia: Nau Llibres-Universitat de València, 2005)

${ }^{15}$ Enrique Javier Díez e Juan Ramón Rodríguez, La "polis" secuestrada: propuestas para una ciudad educadora (Gijón: Trea, 2018)

${ }^{16}$ Jesús Longás et al., "Escuela, educación y territorio. La organización en red local como estructura innovadora de atención a las necesidades socioeducativas de una comunidad", Pedagogía Social Revista Interuniversitaria 15 (2008): 137-154.
} 
perspectivas coas que se asume a obrigatoriedade de atender -por deber e consonte a dereitos-ás persoas, dende a súa infancia ata a vellez.

Con máis voluntarismo que planeamento informado, tendo que lidiar cun aparato burocrático e unha xestión administrativa municipal nada propensa a innovacións que fagan unha lectura laxa da lexislación vixente ${ }^{17}$, foise avanzando. Aínda así, diante do inxente labor a realizar reestruturáronse os servizos municipais, abríronse bibliotecas, organizáronse dun xeito máis coparticipado as festividades locais, recuperáronse tradicións coma 0 antroido e os maios, revisouse con ánimo reparador a memoria local... Coa sensación xeralizada de que todo estaba por facer, o liderado dos concellos como entes territoriais e administracións subsidiarias foi indiscutible e determinante para mellorar a calidade de vida da cidadanía naqueles primeiros lustros de democracia constitucionalizada.

Unha Administración Púbica española de novo cuño estaba a se construir, tendendo cara a progresiva descentralización das súas estruturas e funcións, dos órganos decisorios e das persoas que, individual e colectivamente, deberían asumir a transferencia das competencias do Estado ás Comunidades Autónomas e ás Administracións Locais (Deputacións e Municipios). Leis orgánicas e disposicións normativas de distinto rango foron articulando unha andamiaxe orientada a diversificar as responsabilidades políticas e institucionais na complexa e sempre complicada misión de conciliar a nacionalización co localismo, a xerencialización coa re-politización ${ }^{18}$; mesmo cando os baleiros legais e/ou os escasos orzamentos dificultaban a complicada gobernanza das persoas e dos lugares que habitan, das identidades e das diversidades que as caracterizan. Aludimos a necesidades e demandas -implícitas ou explícitas- que se concretaron en iniciativas dispares, mesmo controvertidas, que foron desde a revitalización do asociacionismo de base ata a recollida selectiva do lixo, pasando pola creación e a posta en marcha de escolas municipais de lecer activo e universidades populares, a creación de parques infantís públicos, a recuperación da toponimia autóctona, a apertura de aulas da cultura e de axencias municipais de lectura, a dotación de ludotecas, de campos de fútbol e pistas polideportivas, a rehabilitación de lavadoiros comunitarios, a consecución de bandeiras azuis para os areais, o trazado de itinerarios didácticos polo contorno, a posta en marcha de programas de educación ambiental, ou a subscrición das primeiras cartas como "cidades educadoras".

A galgante complexidade das realidades sociais locais, no seu diálogo con outros contextos xeográficos e humanos determinando as modificacións lexislativas e as transformacións nos seus sistemas político-administrativos ${ }^{19}$, incidindo na relevancia de promover mudanzas nos eidos económico-laboral, na ordenación e xestión do territorio, a mellora da calidade de vida e do benestar social... acentúan a necesidade de trasladar os discursos -e os programas- políticos á praxe. Dáselle así anovadores significados a verbas que

\footnotetext{
${ }^{17}$ José Luis González, "Que pode achegar o municipio á educación nos níveis non universitarios?", Interea visual 6, (2006): 41-44.

${ }^{18}$ Brugué e Gomá, Gobiernos locales y políticas públicas,1998.

${ }^{19}$ María Belén Caballo, A cidade educadora. Nova perspectiva de organizaçao e intervençao municipal (Porto: Instituto Piaget, 2001), 46.
} 
invocan a participación, o empoderamento, a xustiza e a equidade social, a descentralización, a educación ao longo da vida, a cooperación intermunicipal, o traballo en rede con axentes locais... todas elas fundamentais para converter o espazo municipal nun centro neurálxico para a elaboración doutras políticas, con capacidade para xerar maiores impactos no tocante á optimización dos recursos, dos valores e das oportunidades cun sentido estratéxico ${ }^{20}$. Todo indicaba que cumpría redeseñar o rol dos concellos, avanzando na súa caracterización como administracións relacionais atentas a un maior e mellor desenvolvemento das persoas e das comunidades nas que proxectan a súa convivencia. Nesta teima, a educación reivindicaba -entón, como agora- o seu protagonismo, dentro e fóra das escolas e no territorio.

\title{
0 tímido agromar da educación nos e dos concellos: un quefacer cívico, pedagóxico e político
}

O conxunto da comunidade educa e debe favorecer o educar. Para desenvolver as ensinanzas e as aprendizaxes que permitan construír sociedades democráticas sustentadas no exercízo da cidadanía cómpre ser consciente deste desafío ${ }^{21}$.Así, xa desde mediados dos anos setenta do pasado século, algúns responsables políticos e técnicos municipais nos eidos da educación e a cultura, puxeron o mellor de si mesmos para traducir esta ideaforza en políticas activas, que segundo Candedo, Mosquera, Ojea e Rodríguez-Gómez (1990: 254) ${ }^{22}$ amosaron o seu potencial en dous feitos significativos: dunha banda, na

forte demanda social que se xera pola situación de cambio político que se vive, traducíndose no exercicio das liberdades democráticas e na emerxencia de colectivos que reclaman as súas cotas de participación e o recoñecemento da súa identidade: acceso da muller ó mundo do traballo, crise do modelo de ensino público polos Movementos de Renovación Pedagóxica e os sindicatos, fenómenos do paro xuvenil, etc.;

e doutra, e tras as primeiras eleccións democráticas,

\begin{abstract}
o acceso á xestión política nos Entes locais de persoal có denominador común de teren participado nos diferentes movementos sociais de base (partidos, sindicatos, AAVV, MRPs, etc.), cunha longa experiencia da problemática real existente, satisface-las demandas latentes na sociedade, dotar de equipamentos e servizos tanta veces reivindicados dende fóra, incorporar estruturas e novos profesionais reciclados ó servicio da Administración pública e crear un xermolo de organización política democrática e coordenada, directamente relacionada coa pretensión do que xenericamente poderíamos chamar 'facer cidade'.
\end{abstract}

Con todo, na súa análise subxace unha lectura moi crítica respecto do que será a situación en Galicia -á que consideran "un caso aparte"- a finais dos anos oitenta do pasado século, en comparación co que sucedía nunha grande parte dos concellos do Estado, sen unha planifi-

\footnotetext{
${ }^{20}$ Héctor Pose, La cultura en las ciudades. Un quehacer cívico-social (Barcelona: Graô, 2006).

${ }^{21}$ Emilio Lledó, Sobre la educación. La necesidad de la literatura y la vigencia de la Filosofía (Barcelona: Taurus, 2018).

${ }_{22}$ María Dolores Candedo; María José Mosquera; Rafael Ojea e Xosé Manuel Rodríguez. "Concellos e educación". En José Antonio Caride, dir., A educación en Galicia: informe cero. Problemas e perspectivas (Santiago de Compostela: Instituto de Ciencias da Educación da Universidade de Santiago de Compostela, 1990), 253-264.
} 
cación educativa que poidera considerarse como tal, que resumirían en cinco eivas principais: "non se coñece a realidade, non hai estudos concreto sobre a situación educativa en cada concello, é dicir, un mapa escolar"; "non se dá un mantemento efectivo dos centros en relación co nível competencial dos concellos asignada legalmente o que produce un deterioro de moitas instalacións que requirirán, a medio prazo, fortísimos investimentos"; "A Administración Autonómica e Provincial... fan desleixo das obrigas que lles corresponden, cargando aos concellos a responsabilidade única do mantemento de instalacións mal executadas, que requiren algo máis que un parcheo continuado"; "A Administración Autonómica, responsable última da situación educativa do país, ten sido incapaz de artellar un Plan de Infraestrutura Escolar (PIE) que, baixo a súa coordinación implique tódolos recursos e Administracións con responsabilidades na dignificación da rede escolar de Galicia"; finalmente, constatan

a ausencia dun posicionamento político activo diante do feito educativo". Os concellos galegos -conclúen- "non teñen asumido un papel activo no deseño dunha política educativa municipal acorde co reprantexamento que o novo Estado de feito, esixe..$^{23}$

Fernández Soria e Mayordomo (1993) ${ }^{24}$, admitindo que os confíns do marco que delimita as atribucións e funcións do poder político municipal en materia educativa, no que abundan as "determinacións ambiguas", requiriría dunha maior profundización e implicación dos concellos, afirman a necesidade de que se definan

\begin{abstract}
con verdadeiro enfoque de obxectivos e medios nas accións que se relacionan cos fenómenos educativos; apostar pola consolidación dunha liña de política educativa nos seus programas, que supere ou rebase as actuacións ordinarias ou 'de oficio' e que se diversifique e amplíe alén do escolar, pois seguramente xa temos convido en que o educativo é moito máis que aquilo: comprender a cultura, a festa, o lecer, o medio ambiente, a saúde, o traballo social, a información... Unha estudada política, feita non de accións esporádicas, descoordinadas ou meramente simbólicas.
\end{abstract}

Sen obviar esta liña argumental, que décadas máis tarde aínda define o quefacer municipal -ou, máis ben, a carencia del- nun amplo elenco dos nosos concellos, tamén cabe dicir, poñendo en valor as súas achegas, que desde os últimos anos setenta, os municipios máis proactivos constituiranse en verdadeiras axencias educativas. De partida, comezábase por non confundir a educación coa escolarización ${ }^{25}$, abríndose a perspectivas máis integrais e integradoras do feito de educar á cidadanía ao longo da vida. Nalgúns casos, aceptando o desafío que implicaba -con profesionais formados nos saberes pedagóxicos e, por extensión, nas Ciencias da Educación na Universidade compostelá- observar con cientificidade, pensar e actuar con rigor e avaliar o feito para volver a analisar as súas realidades próximas. Un proceder metódico que facultaba, na súa confluencia coas propostas impulsadas polos responsables políticos elixidos democraticamente, unha toma de decisións informada polo coñecemento, á que se dotaba dunha visión prospectiva a curto

\footnotetext{
${ }^{23}$ Candedo, Mosquera, Ojea e Rodríguez-Gómez, Concellos e educación, 261-262.

${ }^{24}$ José Manuel Fernández Soria e Alejandro Mayordomo, Política educativa y sociedad (Valencia: Univesitat de València, 1993), 207.

25 Jesús Vilar, "Ética e estética do quefacer socioeducativo municipal", Interea visual 6, (2006): 4-6.
} 
e medio prazo, en contraste coa escasa normatividade existente no eido educativo referida aos concellos e a nula bagaxe experiencial previa. Apenas había referentes aos que ollar no territorio próximo. Íase facendo por ensaio e erro, con máis vontade que ciencia, imitando boas prácticas alleas e con escasa avaliación. ${ }^{26}$

Os procedementos e as normas ditadas noutros campos de atención municipal, fundamentalmente en materia urbanística, seguridade, etc. carecían de parangón no ámbito dos servizos persoais á comunidade ${ }^{27}$. Cidades coma Barcelona, Vitoria-Gasteiz ou Girona a nível estatal alumearon un carreiro a seguir durante a década dos oitenta e noventa ás cidades e vilas galegas que asumiron a misión de converter á educación e á cultura en sinais identitarios da súa iniciativa política, en tanto que sectores fundamentais do seu desenvolvemento. Decisións e actuacións políticas nada doadas, tanto en canto, o común obrar non seguía tales preceptos e a falta de lexislación neste orde de cousas, ensumía no desnorte á meirande parte dos gobernos locais, progresistas e conservadores.

No eido socioeducativo e cultural a indefinición de competencias da Lei 7/1985, do 2 de abril, Reguladora das Bases de Réxime Local, implicaba unha considerable ambigüedade na asunción de obrigas co conseguinte risco de asumir servizos pola súa conta. Mantemento dos centros de ensino infantil e primario, limpeza e saneamento, vixilancia da escolaridade obrigatoria, participación nos consellos escolares de centro e apenas pouco máis son as competencias que ostentaban os concellos. Todo o que significaba saírse dese limitador corsé competencial, deixaba ao libre arbitrio o quefacer dos seus responsables. Mais algúns distos xa intuían daquela que os problemas do municipio non eran exclusivos e de responsabilidade única dos cadros políticos e técnicos locais, senón que atinxen á cidadanía e a súa implicación para acadar solución acaída a tales desafíos. Xa que logo, había que afondar no labor pedagóxico de ensinar e facilitar á participación. ${ }^{28}$

O achegamento paulatino a unha "moderna" concepción da política municipal, alentada por un crecente recoñecemento da participación social na mellora da educación ${ }^{29}$ xerou -como xa anticipamos- certa diversidade na adopción de modelos organizativos, denominacións e contratación de persoal cualificado no eido educativo e cultural por parte das corporacións locais. Tamén de labor. Aqueles municipios máis dinámicos e con maiores recursos económicos e sociais, polo xeral e como manifestamos, as cidades e vilas da denominada Galicia atlántica, apostaron por sobrepoñerse as inconcrecións lexislativas e as precariedades orzamentarias e actuar en consonancia cos seus preceptos ideolóxicos. ${ }^{30}$

\footnotetext{
${ }^{26}$ Héctor Pose, La cultura en las ciudades, 87

${ }^{27}$ José Rueda, "Encuadre conceptual, referencial y operativo", Intress, La actuación compactada en los servicios de bienestar social, Colección Surco-3 (1990):79-84.

${ }^{28}$ José Luis Moreno e Sara Colorado, "Participació, ciutat i educación: els consells d'infancia i d'adolescencia", Kul-tur, 6, 171-192.

${ }^{29}$ José Luis Muñoz, Educación y municipio: la importancia de los servicios municipales de educación, Ensayos, Revista de la Facultad de Educación de Albacete 28 (2013) 43-60. http://www.revista.uclm.es/index.php/ensayos. Consultado: 01/10/2018.

${ }^{30}$ Bernat Albaigés, Descentralizació de la política educativa: consolidació, debilitats i crisis (Barcelona: Diputació de Barcelona, Fundació Pi i Sunyer, Fundació Bofill, 2013).
} 
Foi así como nas dúas últimas décadas do século XX, concellos coma Vigo, Santiago de Compostela, A Coruña, Narón, Muros, Culleredo, Oleiros, Allariz, Malpica, Carballo ou Rianxo, significáronse con proxectos de natureza socioeducativa e mesmo apostando por asumir servizos persoais á comunidade ${ }^{31}$. Detrás dese iniciático e importante labor, están nomes propios da política municipal que vislumbraron camiños a seguir, dispuxeron de recursos orzamentais e humanos e posibilitaron que hoxe en día poidamos nomear a referentes da pedagoxía municipal en Galicia coma Rafael Ojea, Xosé Manuel RodríguezAbella, Ana Judel, Alfonso Filgueira, Madó Santos, Héctor Pose, Carme Vidal, Fernando Lavandeira, Pedro Rial, José Luis González, Mari Carmen Castro...Da súa acción profesional e posición ética somos debedores quen traballa na actualidade por manter transitables e idear novos vieiros da intervención socioeducativa municipal en Galicia. Da súa capacidade de iniciativa, non sen algunhas frustracións e desasosegos, merece salientarse

a constitución e/ou desenvolvemento da Coordenadora Galega de Concellos/Educación... [coa participación dos concellos] que de seguido apuntamos: Vigo, Nigrán, Redondela, Moaña, Santiago, Ribeira Rianxo, Corcubión, A Coruña, Culleredo, Oleiros, Fene, Mugardos, As Pontes, Brión, Porto do Son, A Baña, Muros, Arzúa, Negreira, Carballo e Lugo; tendo prevista proximamente a súa incorporación Ourense e Pontevedra. ${ }^{32}$

\section{0 marco competencial dos concellos en educación: feble nas palabras, limitado e insuficiente nas actuacións}

A lexislación educativa de réxime estatal e autonómico constitúe o marco primario que regula, case en exclusiva, a educación en España; mesmo, a pesar de que -coa chegada da democracia aos concellos, nos derradeiros anos setenta- teñen acaecido unha serie de leis que normativizan e regulamentan o labor educativo municipal. Claro está que, no sistema de competencias municipais, poden distinguirse a declaración ou cláusula xeral de competencia, as competencias propias, as delegadas, as actividades complementarias e a xestión ordinaria de competencias propias doutras Administracións ${ }^{33}$. A teor da devandita cláusula xeral, os municipios teñen capacidade potencial para promover toda clase de actividades e prestar cantos servizos públicos contribúan a satisfacer as necesidades e aspiracións das súas comunidades de referencia, sexa por iniciativa propia ou compartida con outras entidades de titularidade pública e ata privada.

En base a isto, ou mesmo contra isto, a amalgama de posibilidades que se abren para os responsables municipais con sensibilidade social é suficiente para exercer labor educativa de calado. Tanto no que se refire ao ensino regrado, escolarizado e curricular, como a esa visión máis ambiciosa do educar ao longo da vida, en calquera tempo e lugar, que temos chamado educación social, comunitaria, cívica... son tarefas suxestivas e atractivas, pero inxentes e, acotío, pouco ou nada recoñecidas para os concellos en termos de

\footnotetext{
${ }^{31}$ Francisco Mareque, "Políticas educativas e departamentos municipais de educación en Galicia", (Tese doutoral: Universidade de Santiago, auto edición, 2011).

${ }^{32}$ Candedo, Mosquera, Ojea e Rodríguez-Gómez, Concellos e educación., 264.

${ }^{33}$ Subirats e Gomá, Gobierno local y educación, 166.
} 
recursos. A Federación Española de Municipios e Provincias (FEMP), consciente deste desaxuste entre medios e necesidades amparándose na ambigüidade lexislativa, leva lustros procurando negociar dita fenda coas restantes Administracións do Estado ${ }^{34}$.

Porque en España non se ten producido a desexable revisión da distribución de competencias atendendo aos prantexamentos que serían esperables, por xustos e necesarios, que xa Pascual Maragall (2002) ${ }^{35}$ situaba na axenda educativa da calidade a educación á que debe aspirar calquera país que teña ansias por transformar as súas realidades a prol da convivencia e do ben común, cuestionando a secular tendencia a aplicar protocolos uniformes e simplificadores, para avogar por un sistema educativo descentralizado: "se se quere avanzar pola senda da autonomía dos centros impónse un reequilibrio das competencias e atribucións que contemple tres niveis diferentes: o centro educativo, a Administración educativa xestora e a Administración educativa reguladora". Neste segundo nivel é onde ten -ao seu xuízo- que xogar un gran papel o municipio como Administración educativa de proximidade, con diversas funcións e competencias, de xeito que este en condicións de exercer o liderado educativo no seu territorio, propoñendo e impulsando un proxecto educativo comunitario, capaz de articular o pacto e o acordo do triángulo formado pola rede educativa, as empresas e a comunidade local. A concepción máis democrática, integral e participativa da educación precisaría desa máis ambiciosa descentralización que non se deu. ${ }^{36}$

\section{Cadro 1. Funcións derivadas das competencias municipais en educación}

\begin{tabular}{|c|l|}
\hline 1 & Participación na programación do ensino \\
\hline 2 & Intervención nos órganos de xestión dos centros públicos \\
\hline 3 & Cooperación na creación, construcción, mantemento e vixilancia dos centros docentes \\
\hline 4 & Participación na vixilancia do cumprimento da escolaridade obrigatoria \\
\hline 5 & Vehicular a relación entre a programación dos centros e o ámbito socioeconómico local \\
\hline 6 & Colaborar cos cnetros no pulo a actividades complementarias extraescolares \\
\hline 7 & Uso dos centros fóra do horario lectivo \\
\hline 8 & Cooperar nos programas de garantía social \\
\hline 9 & Colaborar coas administracións educativas na formación do profesorado \\
\hline 10 & Colaborar na educación infantil e de adultos \\
\hline 11 & Colaborar coas ensinanzas de réxime especial como conservatorios de música e de danza \\
\hline
\end{tabular}

Fonte: Francisco Mareque, Políticas educativas e departamentos municipais de educación en Galicia, Tese Doutoral, 2011. Elaboración propia.

${ }^{34}$ FEMP, www.femp.es, consultado: 02/09/2018.

${ }^{35}$ Pascual Maragall. "Educación, comunidad y calidad de la enseñanza: una nueva agenda educativa". En Informe educativo 2002: la calidad del sistema educativo, edit. Fundación del Hogar del Empleado (Madrid: Santillana, 2002), 32-33.

${ }^{36}$ Muñoz, Educación y municipio, 46. 
En verdade, nunha primeira etapa, a maior parte dos concellos optaron por se limitar a atender as competencias delegadas, reguladas polo art. 27 da LBRR Local e, cunha visión máis laxa, as do art. 28, onde se encadran accións cara a promoción da educación, da cultura, da muller, etc. Un conxunto de competencias que serían referendadas na Lei 5/1997, do 22 de xullo, de Administración Local de Galicia, remitindo ao capítulo IV do Título I a potestade municipal para exercer

a participación na programación da educación e a cooperación coa administración educativa na creación, construción e mantemento dos centros docentes públicos, a intervención nos órganos de xestión dos centros docentes e a participación na vixilancia do cumprimento da escolaridade obrigatoria (art. $80 \tilde{n}) \cdot{ }^{37}$

Ao que cómpre engadir as cláusulas do art. 86 que faculta ao municipio para realizar actividades complementarias relativas á educación, cultura, mocidade, deporte, lecer, etc.

Outra lexislación parella ou complementaria veu a facilitar -incluso a arengar- aos municipios para que incidisen nas tarefas de educar xunto con outros axentes, nomeadamente a escola, os centros de educación de adultos, centros de artes, etc. É o caso da Lei Orgánica 8/1985 de 3 de xullo, reguladora do Dereito á Educación (LODE), ou da Lei Orgánica 1/1990, de 3 de outubro, de Ordenación Xeral do Sistema Educativo (LOXSE). No articulado e disposicións finais de senllas Leis, redáctase unha ampliación das pírricas competencias educativas da Administración local española. O posterior desenvolvemento normativo da LOXSE, xerou o Real Decreto 2274/1993, do 22 de decembro, de cooperación das Corporacións Locais co Ministerio de Educación e Ciencia (MEC) do Goberno de España. No texto, o lexislador contempla a necesidade de ordenar a colaboración entre - MEC e os concellos, incluídas as Deputacións provinciais, para que a formación da cidadanía non se esgote nos centros docentes, senón que se proxecte na vida cidadá perseguindo unha formación integral.

Avanzada a década dos noventa, sería promulgada a Lei Orgánica 9/1995, do 20 de novembro, de Participación, Avaliación e Goberno dos Centros Docentes (LOPEG), coa que se pretendía facultar a participación dun edil no Consello Escolar dos centros do seu municipio. Ademais, acubilla a colaboración das corporacións locais nas actividades escolares complementarias e extraescolares (art. 3.1) e a escolarización do alumnado con necesidades educativas especiais no segundo ciclo de Educación Infantil (disposición adicional segunda). A presenza, non sempre operativizada, de concelleiros/as no seo dos órganos de decisión da comunidade escolar posibilitou un maior coñecemento das súas realidades, contribuíndo a incrementar a conciencia política respecto das necesidades, demandas e potencialidades do educar no contexto local.

Superado o primeiro lustro do novo século, nomeadamente coa publicación da Lei Orgánica 2/2006, do 3 de maio, de Educación (LOE), darase un chanzo máis na cooperación entre as Administracións do público no ámbito educativo. A madureza democrática, non

${ }^{37} \mathrm{M}^{\mathrm{a}}$ Belén Caballo, coord., O Eixo Atlántico: un territorio educador, unha comunidade educativa (Vigo: Eixo Atlántico do Noroeste Peninsular, 2009), 48. 
sen dificultades ou adversidades de diversa índole (restricións orzamentarias, dificultades para acadar un pacto educativo, disputas competenciais, dialéctica público-privado, etc.), dos axentes que fan comunidade, insistirán na reivindicación dunha maior implicación dos responsables políticos na mellora da educación, como unha ferramenta fundamental na construción dunha cidadanía consciente, libre e democrática.

Nesta Lei quedaría redactado de xeito expreso xa no seu preámbulo, ao indicar que que "as sociedades actuais conceden grande importancia á educación que reciben os seus mozo/as, na convicción de que dela dependen tanto o benestar individual coma 0 colectivo.... a educación é o medio mais axeitado para garantir o exercicio da cidadanía democrática, responsable, libre e crítica, que resulta indispensable para a constitución de sociedades avanzadas, dinámicas e xustas". Na disposición adicional décimoquinta -referida aos municipios, corporacións ou entidades locais- alúdese explicitamente a distintas actuacións que poderán promover e/ou que deberán satisfacer, no exercicio das súas funcións, por iniciativa propia e/ou en colaboración con outras Administracións ou entidades. No cadro núm. 2 reflíctense os aspectos nos que incidirían as disposicións lexislativas aprobadas.

\section{Cadro 2. Novos labores educativos desde o municipio en base á LOE}

\begin{tabular}{|c|l|}
\hline 1 & Harmonización da oferta de prazas da rede de centros (art. 109) \\
\hline 2 & Oferta de prazas no primeiro ciclo de educación infantil (art. 15.1) \\
\hline 3 & Acceso ao sistema educativo do alumnado que se incorpore de xeito tardío (art. 78) \\
\hline 4 & Escolarización do alumnado con necesidades específicas (Art. 72) \\
\hline 5 & Educación de Persoas Adultas (art. 66.2) \\
\hline 6 & Acceso á información e á orientación sobre as ofertas de aprendiaxe Permantente (art. 5.6) \\
\hline 7 & Oferta do ensino de Formación Profesional (art.42) \\
\hline 8 & Programas de Cualificación profesional inicial (art. 30) \\
\hline 9 & Accións de natureza compensatoria (art. 80.1) \\
\hline 10 & $\begin{array}{l}\text { Apertura de bibliotecas escolares a toda a comunidade educativa (art. 113.4) e uso das municipais } \\
\text { por parte dos centros (art. 113.5) }\end{array}$ \\
\hline 11 & $\begin{array}{l}\text { Acceso de balde ás bibliotecas e os museos dependentes dos poderes públicos do profesorado } \\
\text { debidamente acreditado (art. 104.3) }\end{array}$ \\
\hline
\end{tabular}

Fonte: Lei Orgánica 2/2006, de 3 de maio, de Educación.

Elaboración propia.

Non obstante, ao paso do tempo, continúan botándose en falta -a pesar dos avances normativos- uns decididos, continuados e concretos procesos de corresponsabilidade política entre as Administracións convocadas a ser partícipes da mellora da educación. Subs- 
cribimos, coincidindo con outros autores, que é imprescindible unha verdadeira vontade de co-xestión mediante un proceso de descentralización e non a mera desconcentración ou delegación de responsabilidades. ${ }^{38}$ Máxime cando a lexislación aprobada xerou interpretacións interesadas e sempre tensas entre as Comunidades Autónomas e os concellos, alén das peculiaridades inherentes a cada territorio. Un caso común: nada xustifica que as Administracións educativas poidan afectar unidades escolares de propiedade municipal sen facerse cargo do gasto que conleva dita afectación. Un centro que imparte 1ำ ciclo de Educación Secundaria Obrigatoria (ESO) depende orzamentariamente do concello, aínda que aí se curse tamén o segundo ciclo das ensinanzas secundarias, cuxo financiamento compete ao goberno autonómico. Isto supón un notable menoscabo para os concellos ao tempo que vulnera a súa autonomía; e, consecuentemente, un cuestionamento das súas potencialidades para camiñar pola senda dunha municipalización do ensino que sexa compatible cunha gobernanza multinível, da que existen aprezables evidencias internacionais. ${ }^{39}$

Articular convenientemente as relacións entre as Administracións sobre a base dunha concepción verdadeiramente descentralizada e operativa da educación, que teña como referente o territorio local, contribuiría a que o pactos educativos tivesen unha máis efectiva concreción nos planos nacional, rexional-autonómico e local, incrementando as posibilidades de optimizar os recursos infraestruturais, materiais e pedagóxicos dispoñibles, acrecentando a eficacia e a eficiencia do seu labor, en cada centro e no conxunto do territorio. Aludimos, inequivocamente, a unha política baseada no diálogo, cooperante e coordinada, sustentada na corresponsabilidade entre as Administracións e a implicación activa dos colectivos que están convocados a construír o dereito á educación, xa desde a primeira infancia: movementos de renovación pedagóxica, asociacións de pais e nais, entidades do terceiro sector e organizacións non gubernamentais, sindicatos do ensino, colexios e asociacións profesionais, etc. Como diría Jordi Borja ${ }^{40}$, "todo isto nos leva ao principio: 0 dereito á cidade e o deber político de facer cidade sobre a cidade para todos. Non estamos prantexando unha pedagoxía que se apoia na cidade, senón a cidade como pedagoxía". A cidade, lida como comunidade, e a pedagoxía prolongada na educación, son dúas das principais metáforas ás que se pode acudir para agrandar os vínculos entre o territorio, as persoas, as políticas educativas locais e a capacidade inclusiva da educación ${ }^{41}$.

\section{Comunidades que educan acrecentando o diálogo educación-sociedade: tres grandes liñas da acción-intervención educativa}

Que as comunidades deben ser educadas, para que elas eduquen, son feitos incontestables. As persoas están cada vez máis afectadas pola omnipresenza das tecnoloxías

\footnotetext{
${ }^{38}$ Xavier Bonal, "La equidad y la cohesión social en las políticas educativas: el papel del ámbito local". En Antonio Merino y José Plana, coords., La ciudad educa: aportaciones para una política educativa local (Barcelona: Ediciones del Serbal, 2007).

${ }^{39}$ Francesc Pedró, "De la municipalización de la enseñanza al gobierno multinivel: evidencias internacionales". En Merino e Plana, La ciudad educa, 31-46.

40 Jordi Borja, "Los desafíos del territorio y los derechos de la ciudadanía". En AAVV: Por una ciudad comprometida con la educación, vol. 2 (Barcelona: Institut d'Educació de l'Ajuntament de Barcelona, 1999), 440.

${ }^{41}$ Merino e Plana, La ciudad educa.
} 
en diversos ámbitos das súas vidas, da circularidade da información e dos coñecementos en múltiples escenarios sociais, con estilos de desenvolvemento individual e colectivo que teñen mudado substancialmente os xeitos de relacionarse entre elas e as sociedades cos seus contornos. ${ }^{42}$

Os desafíos que xeran istos cambios, moitos deles amparados polo eufemismo que conleva asocialos ás "redes sociais", non deberían escurecer o valor do "común" que latexa nos proxectos e traxectos educativos impregnados dunha inequívoca vocación cara 0 encontro, o diálogo, a interacción, os vínculos... tal e como se ten amosado -nas palabras e nos feitos- en experiencias ás que se nomea utilizando expresións como "educación comunitaria", "comunidades de aprendizaxe", "cidades educadoras", "proxectos educativos de cidade", "aulas sen muros", "sociedades pedagóxicas"... Denominacións cun profundo contido pedagóxico-social que relacionan a palabra municipio con outras que falan do ben común, do comunitario.

Dende esta óptica, os municipios galegos foron achegando políticas activas, equipamentos, servizos e programas. Lenta pero decididamente comezaron a ser normais intervencións na liña da que aquí esbozamos. Os seus principais trazos definitorios engonzan de cheo coa implementación dunha filosofía cooperadora entre as escolas e os concellos. Foi notable a visión integral e cada vez máis integradora do quefacer municipal no eido socioeducativo, visualizada a través do establecemento de tres grandes liñas de acción e na crecente inclusión e participación dos diversos axentes que conforman a comunidade educativa, entendida en sentido amplo. Nesta perspectiva os seus enfoques serán, en si e por si mesmos educantes: as políticas que se deseñan e as formas en que se implementen, educan a quen as perceben. As maneiras, ademais dos "contidos" serán portadores de valores.

A meirande parte dos gobernos locais decidiron promover, cun enfoque sectorial, o seu labor dende os Servizos ou Departamentos Municipais de Educación. Malia que a nomenclatura é variada, esta foi a denominación máis común, seguida por aqueloutra que engadía 0 apartado da cultura ${ }^{43}$. Posiblemente 0 fito que marcou 0 punto de saída para exercer un quefacer máis sistemático e efectivo no ámbito educativo foron as I Xornadas Galegas sobre Concellos e Educación, celebradas en Santiago de Compostela en abril de 1985. Froito daquel encontro constituíuse a Coordinadora Galega de Concellos e Educación, xa mencionada, ca pretensión de recoller as sensibilidades municipais no eido educativo, posibilitando o intercambio de experiencias e reforzando a actuación política neste sentido. A pesar de chegar a agrupar, xa na súa constitución, preto de vinte e cinco concellos (apenas un $8 \%$ dos existentes en Galicia), a súa existencia foi máis simbólica que efectiva, por efémera e case testemuñal.

Daquel lembrado encontro saíron dous propósitos principais: o primeiro, afondar na caracterización e reivindicación dos concellos como axentes educadores e posibilitadores

${ }^{42}$ José Antonio Caride e Héctor Pose, "Comunidades que educan" Grial 177 (2008): 36-41.

${ }^{43}$ Francisco Mareque, Políticas educativas e departamentos municipais de educación en Galicia, 183. 
dunha maior e mellor educación da súa veciñanza; o segundo, a recomendación xeral de abordar dende os Departamentos municipais un amplo e diversificado conxunto de competencias en materia educativa, xa fose por iniciativa propia, de modo subsidiario e/ou compartido con outras Administracións Públicas (véxase cadro núm. 3). Quen asinamos a autoría deste texto, participamos naquelas xornadas, que permanecen na nosa lembranza profesional e vital como determinantes na historia da pedagoxía e da educación social en Galicia, mesmo cando era impensable o seu decorrer futuro nas nosas Universidades, tanto no que atinxe ao seu desenvolvemento científico-académico coma profesional. Sendo indisociables das persoas que protagonizaron a súa convocatoria e moitas das que serían, no decorrer do tempo, as súas consecuencias prácticas, vaia dende aquí, de agora e para sempre, tras o seu pasamento en decembro de 2018, o noso emocionado recoñecemento ao pedagogo do Concello de Santiago de Compostela, Xosé Manuel Rodríguez-Abella, referente imprescindible no municipalismo educativo galego.

\section{Cadro 3. Competencias dos Departamentos ou Servizos Municipais de Educación}

\begin{tabular}{|l|l|}
\hline Xestión xeral & $\begin{array}{l}\text { Ordenación do equipo de obras e conserxes dos centros públicos; } \\
\text { supervisión dos servizos contratados no mantemento dos centros; } \\
\text { coordinación das actuacións doutros servizos municipais na escola } \\
\text { (xardíns, auga, seguridade, limpeza...); relación con órganos } \\
\text { técnicos da Consellería de Educación; xestión ordinaria de } \\
\text { expedientes. }\end{array}$ \\
\hline Xestión de competencias & $\begin{array}{l}\text { Conservación e mantemento ordinario dos centros; planeamento } \\
\text { e seguimento de pequenas obras; coñecemento de avaliación } \\
\text { periódica das necesidades dos centros públicos; racionalización } \\
\text { dos gastos derivados das subministracións básicas. }\end{array}$ \\
\hline Planeamento educativo & $\begin{array}{l}\text { Elaboración e actualización do Mapa Escolar; participación no } \\
\text { proceso de distribución da matrícula; estatísticas anuais do ensino; } \\
\text { xestión de solares. }\end{array}$ \\
\hline Dinamización educativa & $\begin{array}{l}\text { Información e asesoramento ao público, ás asociación e entidades } \\
\text { da comunidade educativa; deseño, execución e avaliación da oferta } \\
\text { pedagóxica aos centros; fondo de recursos educativos. }\end{array}$ \\
\hline Participación cidadá & $\begin{array}{l}\text { Secretaría do Consello Escolar Municipal e das súas comisión; } \\
\text { coordinación e asesoramento dos representantes municipais nos } \\
\text { Consellos Escolares dos centros; xestión de expedientes derivados } \\
\text { destes; etc. }\end{array}$ \\
\hline
\end{tabular}

Fonte: Francisco Mareque, Políticas educativas e departamentos municipais de educación en Galicia, Tese Doutoral, 2011.

Elaboración propia.

Agrupar o importante e abundante quefacer educativo desenvolvido, en catro décadas, polos concellos galegos en tres liñas de acción-intervención, responde á inevitable necesidade de resumir -en poucos trazos- a vizosa tipoloxía de iniciativas promovidas neste ámbito, mesmo sendo conscientes de que toda xeralización é inxusta por non entrar nos 
matices, concrecións e/ou singularidades que, sen dúbida, cada unha delas requiriría. En todo caso, facémolo adoptando criterios aos que se teñen remitido distintos autores, no seu día referentes no ámbito da pedagoxía e da educación urbana, como o profesor Antoni Colom ${ }^{44}$.

A primeira categoría de iniciativas alude ás actuacións promovidas en relación co sistema educativo e os centros escolares ubicados no seu territorio. Respecto deles, os concellos afanáronse en mellorar a súa organización e administración (creación de construcións escolares propias coma escolas infantís, mantemento e conservación de edificacións escolares, xestión dos servizos de limpeza e conserxería, etc.); optimización dos servizos e recursos asociados á infraestrutura escolar (dotación de persoal subalterno, equipamento para os centros, comedores, racionalización do transporte, plans de seguridade, eliminación de barreiras arquitectónicas, deseño de patios escolares, etc.); promoción e desenvolvemento de programas de escolarización (subvencións, bolsas e becas de axuda ao estudo, integración escolar do alumnado con necesidades especiais, ludotecas, reciclaxe para ANPAs...) ou dos servizos técnico-educativos (elaboración e actualización de mapas escolares; estudos sectoriais, guías de recursos, etc.). O labor realizado neste ámbito aínda que tivo un alcance xeral, foi dispar no seu grao de desenvolvemento. De novo aquí teríamos que mencionar municipios como os de A Coruña, Santiago de Compostela, Narón e Oleiros, situados na vangarda das propostas mais innovadoras, case sempre respondendo a principios político-ideolóxicos de centro-esquerda e encabalgando sucesivas lexislaturas.

A segunda grande liña de acción-intervención integra os esforzos realizados coa vontade de sobrepoñerse e/ou compensar deficiencias ou lagoas no sistema educativo, fundamentalmente no ensino obrigatorio. Neste sentido cabe mencionar iniciativas de diversa natureza e finalidade, dirixidas tanto aos/ás docentes (convenios de colaboración con seminarios de profesores e MRPs, actividades de reciclaxe profesional, achegamento de materiais didácticos de apoio docente ou fondos municipais de recursos educativos) como ao alumnado (campañas de promoción asociativa, afrontamento do absentismo escolar, prevención e desenvolvemento de hábitos saudables, educación vial, promoción do deporte escolar; educación e sensibilización medioambiental, educación sexual, uso racional das TICs; animación á lectura, educación para a paz, afondamento noutras linguas, etc.). Finalmente, incorporándose a esta segunda grande liña as actividades, deben mencionarse as relativas á educación-animación sociocultural, ás actividades extraescolares e/ou extracurriculares, que viñeron a facilitar un lecer activo, a apertura da escola á comunidade e a conciliación da vida laboral e familiar; todo isto sen obviar a posta en marcha, con xestión directa ou indirecta, de institucións, servizos ou programas pedagóxicos como son as aulas do mar, as granxas-escola, os hortos escolares e urbanos, os museos municipais, a rede de bibliotecas e axencias de lectura, etc.

${ }^{44}$ Antoni Colom, "La educación urbana", en Educación no formal, ed. Jaume Sarramona et al. (Barcelona: Ariel, 1998), 105-126. 
Por fortuna, sería demasiado exhaustivo enumerar polo miúdo cantas accións se teñen desenvolvido baixo estes epígrafes no común dos concellos galegos; entre outras: Programas coma Luditarde ou Camiños escolares seguros do Concello de A Coruña; a colección de unidades didácticas ou o Fondo Municipal de Recursos Educativos do Concello de Santiago de Compostela; a sensibilización medioambiental en Oleiros; a oferta pedagóxica cara a infancia e adolescencia escolarizada en centros públicos dos concellos de Culleredo, As Pontes de García Rodríguez, Carral, Aranga ou Malpica; as redes de lectura pública de Neda, A Coruña ou Oleiros; a aula do mar en Rianxo; 0 afondamento nunha terceira lingua en diversos programas por idades en A Coruña, Vigo ou Santiago de Compostela, etc., etc. Con todo, poñer en valor, significando a relevancia das iniciativas promovidas nestes concellos, non é sinónimo de estabilidade e/ou continuidade dos programas, pois ao longo destas décadas, a fluctuación na perseverancia dos mesmos foi á par dos vaivéns políticos, cambios acontecidos nos responsables técnicos, etc. Mesmo adscribirse ao movemento das "Cidades Educadoras", subscribindo as súas Cartas, non abonda. Algunhas quedaron estancadas, acomodadas no seu quefacer e cun relato esgotado, asociadas á falta autoavaliación ou a revisión e redefinición cada certo tempo do seu modelo. Isto non ten posibilitado dotar de novas miradas a ligazón entre escola e o extraescolar, privándonos de enfocar acaidamente o labor educativo desde e nos concellos. ${ }^{45}$

A terceira liña coincide coa mal chamada "educación non formal" e que nós preferiríamos identificar como educación social, comunitaria, etc.. Trátase daquelas actividades de formación e expansión que ofrezan ao alumnado a alternativa, nos seus tempos libres, de participar en clubes infantís e xuvenís, ludotecas, campamentos urbanos e de verán; de axudar á realización de intercambios entre centros doutras xeografías; de co-organizar certames de arte e literarios; de ofertar campos de traballo en espazos de interese patrimonial... E que, para as familias ou o conxunto da comunidade, tamén implicaron activar ou dar novos folgos a participación nas Escolas de Pais e Nais, en foros de debate (charlas, mesas redondas, etc.), na promoción do emprego, a realización de obradoiros, o desenvolvemento de programas de alfabetización e das escola de adultos, etc. A miúdo, este tipo de accións susténtanse polo achegamento de fondos doutras Administracións, mesmo da Unión Europea a través dos Fondos FEDER ou similares, ou polo labor que desenvolve 0 asociacionismo sen ánimo de lucro, as Fundacións, Padroados, ONGs, Sindicatos, etc.

En gran medida, as cidades-municipio artellaron toda esta argamasa de acción educativa bebendo de proxectos inspiradores xurdidos noutros lares (por exemplo, a Cidade dos Nenos, 1991 en Fermo, Italia, da man do pedagogo Francesco Tonucci) ${ }^{46}$ ou de textos para-legais que as arengaron a implicarse nesta caste de iniciativas; entre outras, o movemento e Carta das Cidades Educadoras (1990) ${ }^{47}$, a Carta Internacional para a Educación

\footnotetext{
${ }^{45}$ Monográfico dedicado a: Miradas educativas en la ciudad: experiencia, cotidianidad y participación, "Converses amb Jaume Carbonell i Jaume Martínez Bonafé", Kultur: revista interdisciplinària sobre la cultura de la ciutat, 5 , vol 3, (2016): 275-296.

${ }^{46}$ www.lacittadeibambini.org/es

${ }^{47}$ www.edcities.org. Aclarar que esta filosofía ten a súa orixe na cidade italina de Turín en 1975 por medio dunha serie de forzas democráticas de esquerdas que entenden que a función educadora non radica únicamente na
} 
do Ocio (1993) ${ }^{48}$, o Manifesto para as Cidades Lentas (1999) ${ }^{49}$; a Axenda 21 da Cultura $(2004)^{50}$, a Carta-Axenda Mundial dos Dereitos Humanos na Cidade (2010) $)^{51}$. A filosofía que alicerza a redacción destes textos entende a educación como unha práctica cotiá alén das escolas e das familias, aínda que as contempla como soportes fundamentais da e para a formación cívica, pero procura implicar a unha ampla gama de axentes e organizacións. A cidade e o territorio educan xa polo feito de selo, dende múltiples esferas e para todos e todas os seus habitantes.

Defender hoxe en día en Galicia o paradigma educacional e cidadán das Cidades Educadoras e/ou de propostas que converxen con elas en nome da cultura, do civismo, dos dereitos humanos, da sustentabilidade...., no que o seu núcleo primordial vén constituído polo coñecemento, a consciencia crítica e o desenvolvemento de novas opcións para a educación das persoas e a mellora das súas realidades, pode que non sexa tan necesario coma hai tres ou catro décadas atrás. Aínda que non por elo haxa que deixar de insistir. A volatilidade de cargos e políticas activas xera que non todo sexa permanente, nin nas adhesións ${ }^{52}$ nin nos programas, orzamentos e persoal, abaneando segundo vontades, modas, recursos económicos ou conflitos de proximidade.

\section{Corolario, a modo de conclusións}

O territorio interroga á Pedagoxía ${ }^{53}$. Ollar desde a educación as súas paisaxes e as comunidades que nel se insiren como pobos, vilas ou cidades, require miradas de amplos horizontes pedagóxicos e sociais. Non só no que nos dan como un tempo e un espazo conformado historicamente, senón tamén como un potencial de futuro respecto do que sempre teremos o inmenso desafío, individual e colectivo, de construírnos como suxeitos da acción e non como meros obxectos de atención, por moito que isto último teña predominado quefacer educacional coñecido. Os novos liderados que emerxen da sociedade civil máis consciente e proactiva, requiren cambios de certa profundidade nos estilos da gobernanza herdados, incidindo moito máis no que se fai coa cidadanía que no que é simplemente para ou cara ela. Ademais, tamén esixe un posicionamento político e cívico moito máis integral e integrador, inclusivo e anovado respecto desafíos educativos, culturais e sociais que deben afrontarse con visión de futuro. Un labor que esixe facer compatibles

escola, senón tamén na cidade. Con certeza, inspiráronse no informe Aprender a ser, dirixido por Edgar Faure para a UNESCO en 1973. A citada Carta tivo posteriores revisións en Bolonia (1994) e Génova (2004).

${ }^{48}$ www.worldleisure.org

${ }^{49}$ www.cittaslow.org

${ }^{50}$ www.agenda21culture.net/es

${ }^{51}$ www.cities-localgoverments.org/CISDP

52 Segundo a nosa consulta 011 de outubro de 2018, tan só os municipios de A Coruña, Ferrol, Lugo, Santiago de Compostela, Ourense, Vigo, Pontevedra e Sanxenxo pertencían á rede de Cidades Educadoras.

${ }^{53}$ Un exemplo foi o proxecto interea (Iniciativas e Recursos no Territorio para a acción educativa e cultural local), auspiciado dende a Deputación da Coruña polo desaparecido deputado Carlos López Crespo co asesoramento de Carlos Varela e deseñado e desenvolvido por un equipo multidisciplinar das Universidades da Coruña e Santiago de Compostela de 2001 a 2009 no seo do grupo de investigación SEPA-interea dirixido por José Antonio Caride. Tratouse, en resume, de diagnosticar, propor e desenvolver múltiples iniciativas para mellorar o quefacer educativo e cultural dos concellos da provincia da Coruña. 
modos dun pensar global para unha acción local cos que invocan as virtudes de pensar localmente para actuar globalmente.

Aínda que non só, será deste xeito como deberán procurar superarse as tensións froito dos problemas da convivencia relacionadas coas desigualdades, os fluxos migratorios, a saturación ou o desleixo do espazo público, a pouca conciencia sobre os dereitos culturais das persoas e o respecto ao medio ambiente..., mitigando, prevendo ou solventando os conflitos que, acotío, xorden entre as institucións e a cidadanía, as políticas públicas locais e as iniciativas de base, os xestores e os creadores, os profesionais e os responsables políticos, etc. Aludimos, xa que logo, a vías de cooperación máis horizontais e co-participadas, que teñan a súa correlación nos avatares -elaboración de propostas, tomada de decisións, execución e operativización das iniciativas, avaliación dos procesos e resultados, etc.- en cuestións especialmente sensibles para a cultura política e a calidade democrática de calquera país e comunidade, como son os orzamentos públicos, a utilización dos espazos físicos e virtuais, a ordenación e os usos do territorio, ou o deseño de plataformas de participación cidadá. ${ }^{54}$

Envolver a unha ampla representación de ámbitos e axentes dos concellos, sexan rurais ou urbanos, no abordamento dos retos daquela, precisa de innovación pedagóxica, vontade e sostenibilidade política, novos marcos de compromiso ${ }^{55}$ e cualificación profesional por parte dos responsables técnicos municipais. Uns e outros deben ter a capacidade de ler destoutro xeito a educación e a cultura de proximidade, na que os municipios están chamados a ser unha ferramenta de liderado con vocación de coordinación e mediación, non de decisión única e vertical. Aprender a delegar e a consensuar, innovar as existentes ${ }^{56}$, deseñar plataformas de encontro e decisión, activar novas ferramentas conceptuais e procedimentais, ter un sentido estratéxico no quefacer e non tanto o de resolver só conflitos... require revisar os prantexamentos máis convencionais da pedagoxía, alentando posicionamentos críticos $^{57}$ que interroguen e que a fagan sentirse interrogada polo territorio e as transformacións dos novos tempos ${ }^{58}$.

Abandonar o rol de goberno xerencial cara a un goberno de carácter relacional aberto á interdependencia, ao diálogo público-privado e, en xeral, a todo canto supón corresponsabilizar aos axentes da comunidade na procura do seu benestar, "promovendo e garantindo a participación cidadá na xestión do desenvolvemento e na toma de decisións públicas....

\footnotetext{
${ }^{54}$ Un caso recente no que tivemos a oportunidade de colaborar foi o deseño e posta en marcha do Laboratorio de Innovación Cidadá do Concello da Coruña (CO-LAB) Ver: http://colab.coruna.gal/

${ }^{55}$ Axenda Educativa Local, Proxecto Educativo Municipal, Administración Relacional, Cultura participativa e Expandida...son denominacións que deben resultar cotiáns aos actuáis xestores políticos, técnicos e axentes da cidade. Neste sentido, o proxecto Brinding (Brinding Social Capital by Participatory and Co-Creative Culture) en Londres é un exemplo. Ver: http://educult-at/en/forschungsprojekte/brinding/ Consultado: 1/10/2018.

${ }^{56}$ Por citar un caso, o Consello Escolar Municipal, ente participativo conformado por persoas con contrastada traxectoria e coñecemento dos fenómenos educativos, debería ter unha lectura máis integral da educación e non circunscribir a súa ollada ás institucións escolares do ensino obrigatorio.

57 Jaume Carbonell, Pedagogías del siglo XXI, (Barcelona: Octaedro, 2015)

${ }^{58}$ Mar Estrela Cerveró, "Mirades educatives a la ciutat: experiencia, quotidianitat i participació", Kultur: revista interdisciplinària sobre la cultura de la ciutat, 6, vol 3 (2016): 19-24.
} 
en congruencia cos dereitos humanos e o cumprimento dos deberes da cidadanía" 59 . As plusvalías que ofrecen os concellos, de asumir o seu rol decididamente educador, virán dadas polos avances que se constaten na asunción de conceptos que impliquen transversalidade, traballo integrado, planeamento estratéxico, horizontalidade na toma de decisións, etc. $O$ caso é que resta camiño por transitar para acadar níveis que, na investigación pedagóxica, gostaríamos ver reflectidos nos concellos galegos, posibilitando que calquera replantexamento da educación como un ben común mundial ${ }^{60}$, ademais de facelos partícipes dunha visión humanística e holística dos procesos de ensino-aprendizaxe, nun mundo diverso e interconectado, brinde a todas as persoas a oportunidade de ter un futuro sostible e unha existencia digna.

\section{Bibliografía}

Albaigés, Bernat. Descentralizació de la política educativa: consolidació, debilitats i crisis. Barcelona: Diputació de Barcelona, Fundació Pi i Sunyer, Fundació Bofill, 2013.

Augé, Marc. Los no lugares: espacios del anonimato. Barcelona: Gedisa, 2006.

Bache, lan e Flinders, Matthew, coords. 2004. Multi-level Governance. Oxford: Oxford University Press.

Borja, Jordi e Castells, Manuel. Local y global: la gestión de las ciudades en la era de la información. Madrid: Santillana-Taurus-UNHCS, 1997.

Borja, Jordi. "Los desafíos del territorio y los derechos de la ciudadanía". En Por una ciudad comprometida con la educación, edit. AA.VV., vol. 2. Barcelona: Institut d’Educació de l'Ajuntament de Barcelona, 1999.

Brugué, Joaquim e Gomá,Ricard coord. 1998. Gobiernos locales y políticas públicas. Barcelona: Ariel,1998.

Caballo, Maria Belén A cidade educadora. Nova perspectiva de organizaçao e intervençao municipal. Porto: Instituto Piaget, 2001.

Caballo, María Belen, coord. 2009. O Eixo Atlántico: un territorio educador, unha comunidade educativa. Vigo: Eixo Atlántico do Noroeste Peninsular, 2009.

Calvo, Aina. La animación sociocultural: una estrategia educativa para la participación. Madrid: Alianza Editorial, 2002.

Candedo, María Dolores; Mosquera, María José; Ojea, Rafael e Xosé Manuel Rodríguez, Xosé Manuel. "Concellos e educación". En A educación en Galicia: informe cero. Problemas e perspectivas, dir, José Antonio Caride, 261-262. Santiago de Compostela: Instituto de Ciencias da Educación da Universidade de Santiago de Compostela, 1990.

\footnotetext{
${ }^{59}$ Eduardo Salvador Vila; José Antonio Caride e María Rosa Buxarrais, "Educación, sostenibilidad y ética: desafíos ante los Objetivos de Desarrollo Sostenible (ODS) (161-196)", en Educación en la sociedad del conocimiento y el desarrollo sostenible, coord., Clara Barroso (La Laguna-Tenerife: Universidad de La Laguna,2018), 187.

60 UNESCO. Replantear la educación ¿hacia un bien común mundial? (París: UNESCO, 2015).
} 
Candedo, María Dolores; Mosquera, María José; Ojea, Rafael e Xosé Manuel Rodríguez, Xosé Manuel. "Concellos e educación". En A educación en Galicia: informe cero. Problemas e perspectivas, dir, José Antonio Caride, 253-264. Santiago de Compostela: Instituto de Ciencias da Educación da Universidade de Santiago de Compostela, 1990.

Carbonell, Jaume. Pedagogías del siglo XXI. Barcelona: Octaedro, 2015.

Caride, José A. e Pose, Héctor. “Comunidades que educan”, Grial, 177, (2008): 36-41.

Caride, José Antonio. "Educación social, ciudadanía y desarrollo en el escenario de las comunidades locales". En Espacios para el desarrollo local, ed. Emilio Lucio-Villegas, 17-61. Barcelona: Editorial PPU, 2006.

Cerveró, Mar Estrela, "Mirades educatives a la ciutat: experiencia, quotidianitat i participació", Kultur: Revista interdisciplinaria sobre la cultura de la ciutat, 6, vol 3 (2016): 19-24.

Colom, Antoni. "La educación urbana". En Educación no formal, edit. Jaume Sarramona et al, 105-126. Barcelona: Ariel, 1998.

Díez, Enrique Javier e Rodríguez, Juan Ramón. La "polis" secuestrada: propuestas para una ciudad educadora. Gijón: Trea, 2018.

Fernández Soria, José Manuel e Mayordomo, Alejandro. Política educativa y sociedad. Valencia: Univesitat de València, 1993.

González, José Luis. "Que pode achegar o municipio á educación nos níveis non universitarios?", Interea visual, 6, (2006): 41-44.

Hooge, Lisbet e Marks. Gary. Multi-level Governance and European Integration. Lanham, MD: Rowman \& Littlefield, 2001.

Lledó, Emilio. Sobre la educación. La necesidad de la literatura y la vigencia de la Filosofía. Barcelona: Taurus, 2018.

Longás, Jesús, et al. "Escuela, educación y territorio. La organización en red local como estructura innovadora de atención a las necesidades socioeducativas de una comunidad", Pedagogía Social Revista Interuniversitaria, 15 (3ª́ época): 137-154.

Mareque, Francisco. "Políticas educativas e departamentos municipais de educación en Galicia", (Tese doutoral: Universidade de Santiago, auto edición, 2011).

Martinell, Alfóns, coord. 2010. Cultura y desarrollo: un compromiso para la libertad y el bienestar. Madrid: Fundación Carolina-Siglo XXI editores.

Moreno, José Luis e Colorado, Sara. "Participació, ciutat i educación: els consells d’infancia i d'adolescencia", Kultur: Revista interdisciplinaria sobre la cultura de la ciutat, 6,vol 3 (2016): 171-192. 
Muñoz, José Luis. "Educación y municipio: la importancia de los servicios municipales de educación", Ensayos, Revista de la Facultad de Educación de Albacete, 28, (2013): 43-60. http://www.revista.uclm.es/index.php/ensayos. Consultado: 01/10/2018.

Orduña, Enrique. Historia del municipalismo español. Madrid: Lustel, 2005.

Pedró, Francesc. "De la municipalización de la enseñanza al gobierno multinivel: evidencias internacionales". En, La ciudad educa, edit, Merino, Ángel e Plana Arrasa, Jordi, 31-46. Barcelona: ediciones del Serbal, 2007.

Pike, Andy, Rodríguez-Pose, Andrés e Tomaney, John. Desarrollo local y regional. Valencia: Instituto Interuniversitario de Desarrollo Local de la Universitat de València, 2011.

Pose, Héctor. La cultura en las ciudades. Un quehacer cívico-social. Barcelona: Graô, 2006.

Rueda, José M. "Encuadre conceptual, referencial y operativo". En Intress, La actuación compactada en los servicios de bienestar social, 79-84. Madrid: Instituto de Trabajo Social y Servicios Sociales, Colección Surco-3, 1990.

Subirats, Joan, coord. 2002. Gobierno Local y Educación: la importancia del territorio y la comunidad en el papel de la escuela. Barcelona: Ariel.

Vila Merino, Eduardo S.; Caride, José Antonio e Buxarrais, María Rosa. "Educación, sostenibilidad y ética: desafíos ante los Objetivos de Desarrollo Sostenible (ODS) (161196)" En Educación en la sociedad del conocimiento y el desarrollo sostenible, (coordª) Clara Barroso, 187. La Laguna-Tenerife: Universidad de La Laguna,2018.

Vilar, Jesús. "Ética e estética do quefacer socioeducativo municipal", Interea visual, 6 (2006): 4-6. 